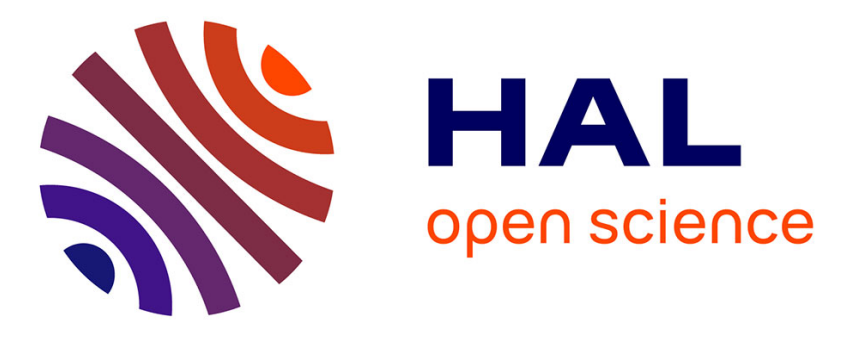

\title{
Complexities in the Molecular Spin Crossover Transition
}

Xin Zhang, Sai Mu, Guillaume Chastanet, Nathalie Daro, Tatiana Palamarciuc, Patrick Rosa, Jean-François Létard, Jing Liu, George E. Sterbinsky, Dario A. Arena, et al.

\section{- To cite this version:}

Xin Zhang, Sai Mu, Guillaume Chastanet, Nathalie Daro, Tatiana Palamarciuc, et al.. Complexities in the Molecular Spin Crossover Transition. Journal of Physical Chemistry C, 2015, 119 (28), pp.1629316302. 10.1021/acs.jpcc.5b02220 . hal-01180480

\section{HAL Id: hal-01180480 https://hal.science/hal-01180480}

Submitted on 22 Jan 2021

HAL is a multi-disciplinary open access archive for the deposit and dissemination of scientific research documents, whether they are published or not. The documents may come from teaching and research institutions in France or abroad, or from public or private research centers.
L'archive ouverte pluridisciplinaire HAL, est destinée au dépôt et à la diffusion de documents scientifiques de niveau recherche, publiés ou non, émanant des établissements d'enseignement et de recherche français ou étrangers, des laboratoires publics ou privés. 


\section{Complexities in the Molecular Spin Crossover}

\section{Transition}

Xin Zhang, ${ }^{\dagger}$ Sai Mu, ${ }^{\dagger}$ Guillaume Chastanet, ${ }^{\S}$ Nathalie Daro, ${ }^{\S}$ Tatiana Palamarciuc, ${ }^{\S \&}$ Patrick

Rosa, ${ }^{\S}$ Jean-François Létard, ${ }^{\S}$ Jing Liu, ${ }^{\ddagger} \|$ George E. Sterbinsky, " Dario A. Arena, "Céline Etrillard, ${ }^{\perp}$ Bohdan Kundys, ${ }^{\perp}$ Bernard Doudin, ${ }^{\perp}$ Peter A. Dowben $*{ }^{\dagger}$

${ }^{\dagger}$ Department of Physics and Astronomy, University of Nebraska-Lincoln, Lincoln, NE, U.S.A.

${ }^{\S}$ CNRS, Univ. Bordeaux, ICMCB, UPR 9048, F-33600 Pessac, France.

$\$$ Department of Chemical Engineering, Northeastern University, Boston, MA, U.S.A.

॥ National Synchrotron Light Source, Brookhaven National Laboratory, Upton, NY, U.S.A.

${ }^{\perp}$ Institut de Physique et Chimie des Matériaux de Strasbourg (IPCMS), Université de Strasbourg, UMR 7504 CNRS-UdS, 23, rue du Lœss B.P. 20, 67034 Strasbourg, France

${ }^{\&}$ Current address : Department of General and Analytical Chemistry, State University of Moldova, 60, street A. Mateevici, Chisinau, Moldavia

KEYWORDS: molecular spin crossover transitions, electronic structure changes, X-ray absorption spectroscopy. 


\section{ABSTRACT}

Variable temperature studies of the electronic structures of four different Fe(II) spin crossover molecules, $\quad\left[\mathrm{Fe}\left(\mathrm{H}_{2} \mathrm{~B}(\mathrm{pz})_{2}\right)_{2}\right.$ (bipy) $\quad(\mathrm{pz}=$ pyrazol-1-yl, $\quad$ bipy=2,2'-bipyridine $)$, $\left[\mathrm{Fe}\left(\mathrm{H}_{2} \mathrm{~B}(\mathrm{pz})_{2}\right)_{2}(\mathrm{phen})\right], \quad\left[\mathrm{Fe}(\text { phen })_{2}(\mathrm{NCS})_{2}\right] \quad($ phen $=\quad 9,10$-phenantroline $), \quad$ and $\quad[\mathrm{Fe}(\mathrm{PM}-$ $\left.\mathrm{AzA})_{2}(\mathrm{NCS})_{2}\right] \quad(\mathrm{PM}-\mathrm{AzA}=4$-phenyldiazenyl-N-(pyridin-2-ylmethylene)aniline) $\quad$ by $\quad \mathrm{X}$-ray absorption spectroscopy (XAS), combined with electrical properties studies of [Fe(PM$\mathrm{AzA})_{2}(\mathrm{NCS})_{2}$ ] single crystal are presented. We show that both the XAS signature of the powdered spin state sample and the dielectric permittivity of the $\left[\mathrm{Fe}(\mathrm{PM}-\mathrm{AzA})_{2}(\mathrm{NCS})_{2}\right]$ single crystal change at significantly lower temperatures than the magnetometry, structure, and resistivity indicators of a spin crossover transition. These findings suggest that the electronic structure phase ordering process does not simply follow the spin transition. The changes in electronic structure are in agreement with the expectations from density functional theory (DFT) results for the different molecular electronic structures associated with the high spin and low spin states.

\section{INTRODUCTION}

The spin crossover ( $\mathrm{SCO}$ ) phenomenon, occurring in various $3 d$ transition metal compounds, is associated with changes to molecular electronic structure, as a consequence of the splitting of the energy of the transition metal d orbitals, for example into $t_{2 g}$ and $e_{g}$ when set in octahedral ligand fields. ${ }^{1-8}$ There is a rich body of experimental work indicating that SCO transition can be induced by a change in temperature, pressure, light, magnetic and electric fields. ${ }^{9-13}$ Spin 
crossover induced by temperature is most frequently studied, typically with the transition identified by a change of magnetic moment and modification of structural properties and crystal packing of the spin crossover molecules. Magnetic measurements are considered as the key experimental indicator of the SCO molecular state, typically making a transition from a diamagnetic low spin (LS) state at low temperatures to a paramagnetic high spin (HS) state at high temperatures for the most studied class of complexes based on $\mathrm{d}^{6} \mathrm{Fe}(\mathrm{II})$ cation.

A recognized complication in the thermal SCO transition is the occurrence of cooperative behavior that possibly results in thermal hysteresis. ${ }^{1,2,5,11,14-16}$ The steric hindrance of the change of molecular conformations when modifying the molecules spin state results in the thermal stabilization and persistence of a given spin state when sweeping the temperature. Furthermore, a mix of states is often observed at a given temperature. There is therefore a shared convention defining a 'transition' temperature as the temperature where there are equal numbers of molecules in the two spin states $\left(\mathrm{T}_{1 / 2}\right)$. Further complications result from the possible metastable stabilization of the high-temperature (usually HS) spin state. The best-documented example is light activation of the high spin state (light-induced excited spin-state trapping or LIESST), at temperatures well below the SCO transition temperature $\left(T_{1 / 2}\right)$, where the low spin state should be dominant. ${ }^{3,5,14,17-23}$ LIESST requires the experiments be performed at lower temperatures, in order to thermally stabilize a metastable light-induced high spin state that may be or not similar to the thermodynamic paramagnetic HS state at high temperature. At higher temperatures, approaching SCO transition temperature $\left(\mathrm{T}_{1 / 2}\right),{ }^{14,18-23}$ thermally induced relaxation causes the light-induced excited spin-state to collapse to the thermodynamic ground state that is the low spin state at those temperatures below $\mathrm{T}_{1 / 2}$, i.e. the optical excitation does not stabilize the high spin state to elevated temperatures. 
Organic and molecular electronics research fields have become increasingly interested in switching molecular entities, with SCO among the candidates for molecular switching transport studies. This has drawn attention to the implications of SCO transition on transport properties. ${ }^{9-}$ 11,16,24-26 The spectroscopic signature of the SCO transition, particularly of the unoccupied electronic states, has been shown to be a powerful indication of electronic changes between high and low spin states, ideally suited for thin films studies. ${ }^{10,17-19,27-33}$ Electron-induced (IESST) ${ }^{9}$ and soft X-ray induced excited spin state trapping (SOXIESST) ${ }^{18}$ (meta)stabilization of the high spin states at low temperatures has also been reported. Again, it is possible to observe a dominant high spin phase at the lowest temperatures, while the low spin phase re-appears at temperature approaching the transition, where thermal excitations free the system from the quenched hightemperatures state.

The question must be asked as to whether the spectroscopic signature of the SCO transition need follow the SCO spin transition, as determined in magnetometry, in "lock-step", as has been claimed. ${ }^{18}$ It is therefore of primary importance to check if the temperature stability of a given spin state depends on the experimental probing techniques, as the excitation might be invasive, up to the point it provides opportunities to the system under study to reach a metastable state in a complicated energy landscape. This becomes particularly critical for investigations targeting thin films of molecular thickness, better suited for large electric field stress, and probed with spectroscopic tools using significant irradiation doses required for solving signal-to-noise issues. This is especially true, because of the clear evidence for extrinsic factors to affect spin crossover transition, including stabilization of the spin state by an electric field. ${ }^{33}$ 


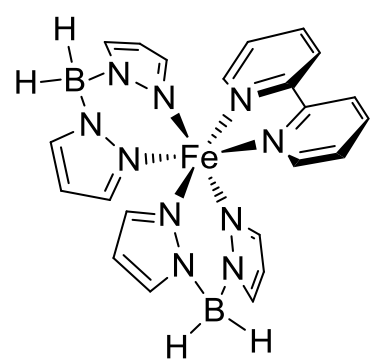

$\left[\mathrm{Fe}\left(\mathrm{H}_{2} \mathrm{~B}(\mathrm{pz})_{2}\right.\right.$ (bipy) $]$

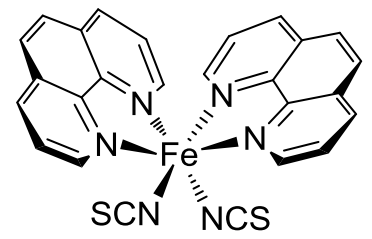

$\left[\mathrm{Fe}(\text { phen })_{2}(\mathrm{NCS})_{2}\right]$

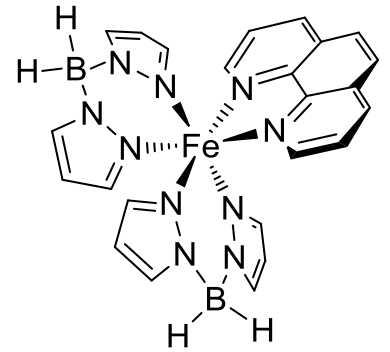

$\left[\mathrm{Fe}\left(\mathrm{H}_{2} \mathrm{~B}(\mathrm{pz})_{2}(\right.\right.$ phen $\left.)\right]$

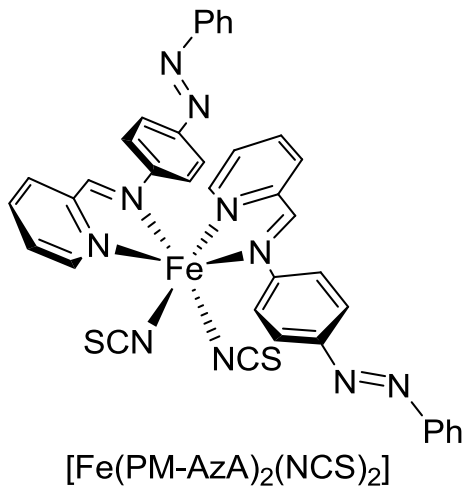

Figure 1. Schematics of the Fe(II) spin crossover complexes $\left[\mathrm{Fe}\left(\mathrm{H}_{2} \mathrm{~B}(\mathrm{pz})_{2}\right)_{2}\right.$ (bipy)] (bipy=2,2'bipyridine), $\left[\mathrm{Fe}\left(\mathrm{H}_{2} \mathrm{~B}(\mathrm{pz})_{2}\right)_{2}(\right.$ phen $\left.)\right]$, [Fe(phen $\left.)_{2}(\mathrm{NCS})_{2}\right]$, and $\left[\mathrm{Fe}(\mathrm{PM}-\mathrm{AzA})_{2}(\mathrm{NCS})_{2}\right](\mathrm{PM}-\mathrm{AzA}=4-$ phenyldiazenyl-N-(pyridin-2-ylmethylene)aniline). For clarity, some hydrogen is not shown.

We mostly focus our attention here on X-ray absorption spectroscopy (XAS), possibly resulting in soft x-ray induced excited spin state trapping (SOXIESST), which is documented for $\mathrm{Fe}(\mathrm{bpz})_{2}$ (phen) (pz=pyrazol-1-yl, phen=9,10-phenantroline). ${ }^{19}$ These findings raise the question of whether the excitation spectroscopies are representative of the fully relaxed spin state of a molecule at finite temperature. To explore these possible complexities in SCO transition we have sought to compare the temperature dependence of the magnetic, structural, electrical, and electronic structure of spin crossover complexes. In order to avoid further difficulty in transition 
temperature interpretation, we focus our attention on systems (Figure 1) that exhibit little thermal hysteresis of the spin state while being in the crystalline form: $\left[\mathrm{Fe}\left(\mathrm{H}_{2} \mathrm{~B}(\mathrm{pz})_{2}\right)_{2}(\mathrm{bipy})\right]$ (bipy=2,2'bipyridine), $\quad\left[\mathrm{Fe}\left(\mathrm{H}_{2} \mathrm{~B}(\mathrm{pz})_{2}\right)_{2}(\mathrm{phen})\right], \quad\left[\mathrm{Fe}(\mathrm{phen})_{2}(\mathrm{NCS})_{2}\right], \quad$ and $\quad\left[\mathrm{Fe}(\mathrm{PM}-\mathrm{AzA})_{2}(\mathrm{NCS})_{2}\right] \quad(\mathrm{PM}-$ AzA=4-phenyldiazenyl-N-(pyridin-2-ylmethylene)aniline). All are possible candidates for thin films sublimation in high-vacuum conditions.

\section{METHODS}

$\left[\mathrm{Fe}\left(\mathrm{H}_{2} \mathrm{~B}(\mathrm{pz})_{2}\right)_{2}\right.$ (bipy)] and $\left[\mathrm{Fe}\left(\mathrm{H}_{2} \mathrm{~B}(\mathrm{pz})_{2}\right)_{2}(\mathrm{phen})\right]$ were synthesized according to reference [34]. $\left[\mathrm{Fe}(\text { phen })_{2}(\mathrm{NCS})_{2}\right]$ and $\left[\mathrm{Fe}(\mathrm{PM}-\mathrm{AzA})_{2}(\mathrm{NCS})_{2}\right]$ were synthesized according to references [35] and [36] respectively.

X-ray absorption spectroscopy measurements of $\left[\mathrm{Fe}\left(\mathrm{H}_{2} \mathrm{~B}(\mathrm{pz})_{2}\right)_{2}(\mathrm{bipy})\right],\left[\mathrm{Fe}\left(\mathrm{H}_{2} \mathrm{~B}(\mathrm{pz})_{2}\right)_{2}(\mathrm{phen})\right]$, $\left[\mathrm{Fe}(\mathrm{phen})_{2}(\mathrm{NCS})_{2}\right]$, and $\left[\mathrm{Fe}(\mathrm{PM}-\mathrm{AzA})_{2}(\mathrm{NCS})_{2}\right]$ powders were performed at the $\mathrm{U} 4 \mathrm{~B}$ beamline at the National Synchrotron Light Source at Brookhaven National Laboratory. ${ }^{37}$ The measurements were taken in the total electron yield (TEY) mode of operation across the Fe $2 p_{3 / 2}$ or $\mathrm{L}_{3}$ edge and Fe $2 p_{1 / 2}$ or $\mathrm{L}_{2}$ edge. The collected spectra were normalized by incident beam intensity monitored by a Au mesh mounted upstream of the sample chamber, and the $\mathrm{Fe}_{3,2}$ edge spectrum of an iron oxide $\left(\mathrm{Fe}_{2} \mathrm{O}_{3}\right)$ film was measured as an accompaniment to the XAS data for each molecular complex sample as reference for alignment and calibration. The Fe $2 \mathrm{p}_{3 / 2}$ or $\mathrm{L}_{3}$ edge measured in the high spin (HS), or higher temperature spin state, at $705.3 \pm 0.3 \mathrm{eV}$ photon energy (Figure 1) is in rough agreement with the values of $704.9 \mathrm{eV},{ }^{10,17,31} 705.5 \mathrm{eV}^{29,30,33}$ but lower than the values of $705.9 \mathrm{eV}^{19}$ to $706.5 \mathrm{eV}^{18}$ previously measured for Fe based spin crossover complexes. These differences in the $\mathrm{Fe} 2 \mathrm{p}_{3 / 2}$ or $\mathrm{L}_{3}$ edge are easily attributable to differences in calibration 
Characterization of the crystal size expansion and electrical properties, performed on [Fe(PM$\mathrm{AzA})_{2}(\mathrm{NCS})_{2}$ ] single crystals, were taken on the same crystal in the same environment (pressure in the $10^{-5}$ mbar range in a pumped cryostat). Crystal expansion was measured using a sensitive capacitance dilatometer, ${ }^{38}$ with AC and DC electrical properties simultaneously recorded by an impedance meter (Agilent E4980A).

The first-principles calculations were carried out using projected augmented wave method $(\mathrm{PAW})^{39}$ as implemented in the Vienna ab initio simulation package (VASP). ${ }^{40,41}$ We used the plane-wave energy cutoff of $500 \mathrm{eV}$ and the $\Gamma$ point for the Brillouin zone integration. The experimental structures were applied a single molecule then embedded in a $50 \times 50 \times 50 \AA^{3}$ cubic unit cell. Gaussian smearing of $0.1 \mathrm{eV}$ was adopted for the static calculations. Both the HS state and LS state were obtained to confirm the ground state for the different molecules. To describe the electronic structure correctly, we used the rotationally invariant local density approximation $($ LDA $)+U$ method $^{42}$ but with no LSDA exchange splitting. We set the onsite correlation energy $U=5.0 \mathrm{eV}$ and exchange energy $J=0.9 \mathrm{eV}$ for localized $3 d$ orbitals on Fe atoms, but we have investigated the Hubbard $U$ dependence of our results (see supplementary materials) and find some variation in the $e_{\mathrm{g}} / t_{2 \mathrm{~g}}$ ratios in both LS and HS states for different choices of the onsite correlation energy $U$. 

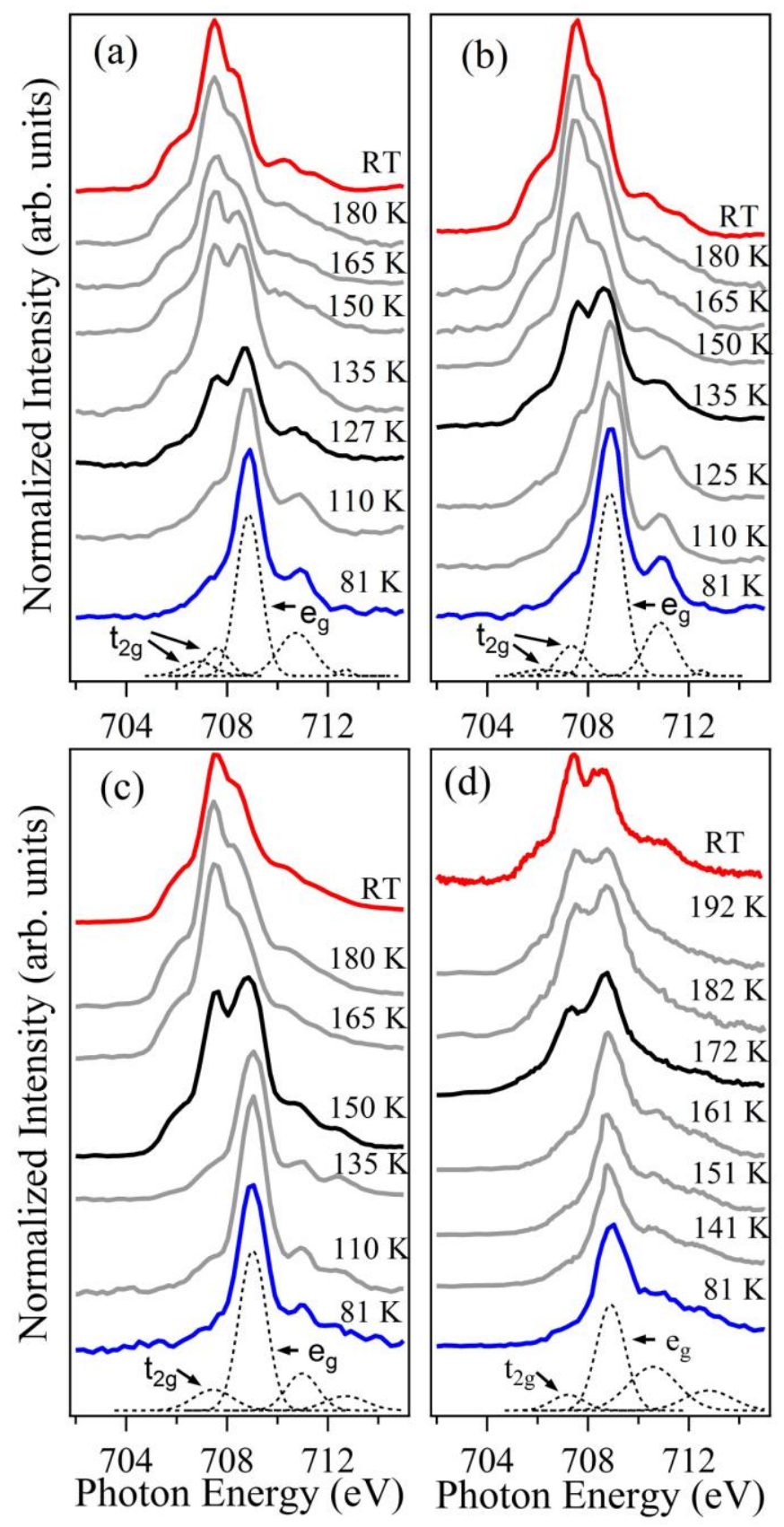

Figure 2. The temperature dependent X-ray absorption spectra of (a) $\left[\mathrm{Fe}\left(\mathrm{H}_{2} \mathrm{~B}(\mathrm{pz})_{2}\right)_{2}(\right.$ bipy $\left.)\right]$, (b) $\left[\mathrm{Fe}\left(\mathrm{H}_{2} \mathrm{~B}(\mathrm{pz})_{2}\right)_{2}(\mathrm{phen})\right]$, (c) $\left[\mathrm{Fe}(\text { phen })_{2}(\mathrm{NCS})_{2}\right]$, and (d) $\left[\mathrm{Fe}(\mathrm{PM}-\mathrm{AzA})_{2}(\mathrm{NCS})_{2}\right]$. Red indicates spectra mostly indicative of the high spin (HS) state, blue, mostly of the low spin (LS) state and black indicates spectra taken within the range of the thermal transition with resulting mixed spin states. 


\section{ASSIGNMENT OF THE UNOCCUPIED MOLECULAR ORBITALS}

The Fe L-edge X-ray absorption (XAS) spectra are representative of state to state transitions of electrons excited from $\mathrm{Fe} 2 p$ orbital to $3 d$ empty orbitals. Other intra-atomic $\mathrm{Fe}$ transitions from $2 p$ to $4 s$ are of low probability while excitations to $4 p$ are dipole forbidden. So analysis of the XAS Fe L-edge spectra will emphasize the Fe $3 d$ weighted empty orbitals. For the Fe based spin crossover molecular systems under consideration, in the low spin state, the six $3 d$ electrons are paired and occupy the three $t_{2 g}$-like orbitals leaving the $e_{g}$-like orbitals empty. In high spin state, the $e_{g}$ set is filled with two unpaired electrons while four electrons occupy the three orbitals of the $t_{2 g}$. The usually degenerate ${ }^{5} \mathrm{~T}_{2 \mathrm{~g}}$ is generally orbitally quenched by the deviation of molecular geometry from the perfect octahedron. Figure 2 illustrates that the changes in the X-ray absorption spectroscopy (XAS) features, across the spin crossover transition, are generally similar for $\left[\mathrm{Fe}\left(\mathrm{H}_{2} \mathrm{~B}(\mathrm{pz})_{2}\right)_{2}(\right.$ bipy $\left.)\right],\left[\mathrm{Fe}\left(\mathrm{H}_{2} \mathrm{~B}(\mathrm{pz})_{2}\right)_{2}(\mathrm{phen})\right], \quad\left[\mathrm{Fe}(\mathrm{phen})_{2}(\mathrm{NCS})_{2}\right]$, and $[\mathrm{Fe}(\mathrm{PM}-$ $\mathrm{AzA})_{2}(\mathrm{NCS})_{2}$ ], and resemble those of prior work. ${ }^{10,17,31,33}$ Although the signal is smaller, these signature changes in the XAS spectra at the $\mathrm{Fe} \mathrm{L}_{3}, \mathrm{Fe} 2 \mathrm{p}_{3 / 2}$ core, edge are also seen at the Fe L2, Fe 2p1/2 core, edge (supplementary materials).

In order to better understand the XAS spectra, we compare our XAS results with the Fe weighted unoccupied $\mathrm{e}_{\mathrm{g}}$ and $\mathrm{t}_{2 \mathrm{~g}}$-like states for both the high spin and low spin molecular states calculated by means of density functional theory (DFT). The DFT calculations were based on the published molecular structures of $\left[\mathrm{Fe}\left(\mathrm{H}_{2} \mathrm{~B}(\mathrm{pz})_{2}\right)_{2}(\right.$ bipy $\left.)\right],{ }^{43} \quad\left[\mathrm{Fe}\left(\mathrm{H}_{2} \mathrm{~B}(\mathrm{pz})_{2}\right)_{2}(\mathrm{phen})\right],{ }^{43}$ $\left[\mathrm{Fe}(\mathrm{phen})_{2}(\mathrm{NCS})_{2}\right],^{44}$ and $\left[\mathrm{Fe}(\mathrm{PM}-\mathrm{AzA})_{2}(\mathrm{NCS})_{2}\right]^{7}$ for high spin and low spin states. The resulting Fe weighted partial density of states (DOS) is shown in Figure 3 for spin crossover 
complex $\left[\mathrm{Fe}\left(\mathrm{H}_{2} \mathrm{~B}(\mathrm{pz})_{2}\right)_{2}(\right.$ bipy $\left.)\right]$, and correspond to the XAS spectral features, as indicated in Figure 2a.
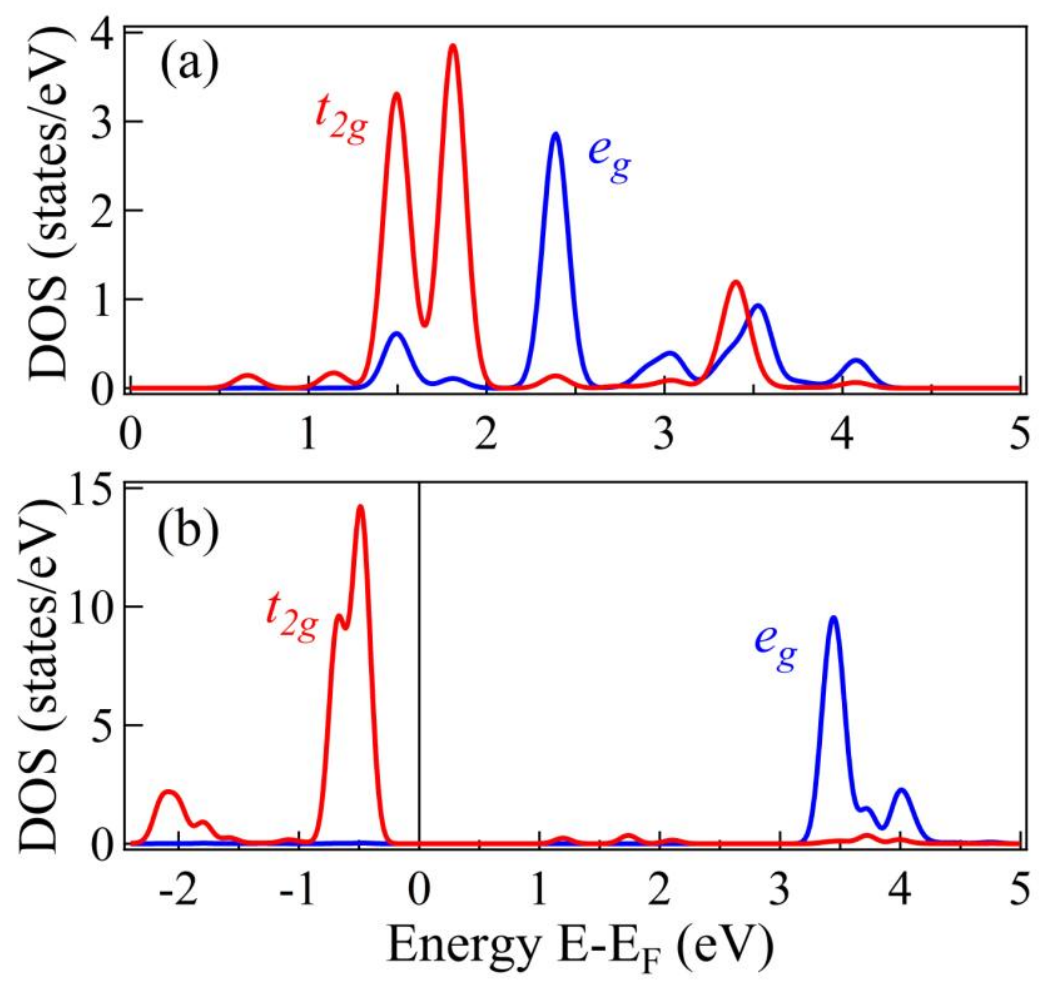

Figure 3. $\left[\mathrm{Fe}\left(\mathrm{H}_{2} \mathrm{~B}(\mathrm{pz})_{2}\right)_{2}\right.$ (bipy)] DFT calculations for the high spin state (a) and low spin state (b) Fe partial density of $3 d$ empty states: $e_{g}$ (blue) and $t_{2 g}$ (red). Energies referenced to the chemical potential as $E-E_{F}$.

The interpretation and conclusions for the other molecules are similar, with partial density of states similar to Figure 3 and the full density of states calculations detailed in the supplementary materials and elswhere. ${ }^{45}$ Thus, although there are clearly differences in the XAS spectral weight components, depending on the ligands, as seen in Figure 2, there is good correspondence with theory (supplementary materials) and the trends are similar for all of the complexes studied. We are aware that the DFT description of the electronic excited states is flawed and direct 
comparison with spectroscopy is typically poor. One difficulty is the level alignment, i.e. the position of Kohn-Sham orbitals is not accurate due to the exaggerated self-interaction in DFT itself. ${ }^{4-48}$ Thus the positions of the unoccupied states (electron affinity) are not reliable within DFT, as widely acknowledged. Since our purpose is simply to identify the unfilled levels, and compare the relative position and relative weight of those levels, we do not go beyond DFT, though some problems with DFT might be alleviated by inclusion of delta-SCF (self consistent field) methods and perturbative inclusion of many-body effects. Thus these calculations do not include the multiple final states that further broaden the XAS spectral features, nor is theory corrected for matrix element effects.

In principle, for the high spin state, the unoccupied $3 d$ weighted molecular states contain both $t_{2 g}$-like and $e_{g}$-like orbitals, while the unfilled $3 d$ in a low spin state contain mainly $e_{g}$ orbitals. This simple fingerprint is confirmed and illustrated by the DFT calculations, with a partial density of $3 d$ empty states shown in Figure 3, clearly showing the differences in the density of states above the Fermi energy, accessible by XAS. Since the ligand field on Fe site is a distortion of octahedral symmetry, assignment of the $3 d$ states, with lower-lying $t_{2 g}$-like and higher-lying $e_{g}$-like states, is only an approximate symmetry label. Because of the distortion from octahedral symmetry, it is worth noting that both the nominally $t_{2 g}$ and $e_{g}$ states, in reality, are split reflecting the overall lower point group symmetry. There is clearly an enhancement of several $t_{2 g}$-like low lying unfilled molecular orbitals in the high spin state, which are suppressed in the high spin state. These changes seen in the DFT calculations in regard to the lower-lying $t_{2 g}$-like unoccupied state placement are consistent with the addition of $\mathrm{t}_{2 \mathrm{~g}}$ weight at the bottom of the conduction band (or lowest unoccupied molecular orbitals) and below the unoccupied $\mathrm{e}_{\mathrm{g}}$ molecular orbital spectral density. Qualitatively these changes reflect the change in unoccupied 
density of states seen in inverse photoemission spectroscopy (IPES) $)^{32,33}$ and at the $\mathrm{Fe}_{3}$ edge XAS, ${ }^{1,10,17-19,28-31,33}$ as one goes from the low spin state to high spin state for the Fe based spin crossover molecular complexes, as illustrated in Figure 3 and observed in Figure 2. This is the origin of the changes in the low lying unoccupied molecular orbital $t_{2 g} / e_{g}$ density of states ratio with temperature.

Not only do the different molecular spin states lead to differences in the occupation of $t_{2 g}$ and $e_{g}$ states, but this contrast also depends on the ligand field. This is seen in the XAS spectra of Figure 2, as differences in the spectral weight ratio of the nominlly " $e_{g} / t_{2 g}$ " symmetry low lying unoccupied molecular orbitals in the $\mathrm{Fe}_{2}$-edge spectra. From DFT calculations, we can diagonalize the density matrix, and obtain the eigen states of the density matrix and the occupation number for each state. For the lower lying $t_{2 \mathrm{~g}}$ orbitals in $\left[\mathrm{Fe}\left(\mathrm{H}_{2} \mathrm{~B}(\mathrm{pz})_{2}\right)_{2}(\right.$ bipy $\left.)\right]$ for both HS and LS states, we find a mixture between $d_{\mathrm{yz}}$ and $d_{\mathrm{xz}}$. The corresponding eigenstates for $t_{2 \mathrm{~g}}$ orbitals are $d_{\mathrm{xy}},(1 / \sqrt{2})\left(d_{\mathrm{yz}}-d_{\mathrm{xz}}\right)$ and $(1 / \sqrt{ } 2)\left(d_{\mathrm{yz}}+d_{\mathrm{xz}}\right)$. All $t_{2 \mathrm{~g}}$ orbitals are occupied in low spin state in both spin channels. In high spin state, the $(1 / \sqrt{ } 2)\left(d_{\mathrm{yz}}+d_{\mathrm{xz}}\right)$ is occupied in only one (majority) spin channel while empty in another spin channel. Quantitatively, by counting the partial occupation density of each orbital, we can estimate from our DFT calculations that the $e_{\mathrm{g}} / t_{2 \mathrm{~g}}$ ratios for $\left[\mathrm{Fe}\left(\mathrm{H}_{2} \mathrm{~B}(\mathrm{pz})_{2}\right)_{2}\right.$ (bipy) $]$ are $\square \square \square \square \square$ for the high spin state and $\square 5$ for the low spin state, although these ratios are uncorrected for matrix element and final state effects. The $e_{\mathrm{g}} / t_{2 \mathrm{~g}}$ ratio, in HS state, is quite inert to the choice of Hubbard $U$ parameter, whereas in LS state, the $e_{\mathrm{g}} / t_{2 \mathrm{~g}}$ ratio varies from 3.8 to 5.8 in the range of $3 \mathrm{eV} \leq U \leq 6 \mathrm{eV}$ (details in supplementary materials). This is remarkably consistent with the XAS analysis (Figure 4(a)), which indicates empirical values of $0.7 \pm 0.2$ for the high spin state and $\sim 5$ for the low spin state. 
As explained elsewhere, ${ }^{1,5,7,43-44,49-50}$ and confirmed by our own DFT model calculations, the change in the molecular spin state is associated with an intramolecular structural change, dominated by the metal center to ligand covalent bond length changing, i.e. between Fe and $\mathrm{N}$ atoms in our cases, which is a thermally reversible process. At the structural change, modifying the pseudo-octahedral molecule field drives the spin crossover, and therefore the changes in electronic structure should be associated with the changes in the molecular spin state. The ratio of " $e_{g} / t_{2 g}$ " empty orbitals does change with ligand, as seen in Figure 2, and confirmed by theory (supplementary materials). Nevertheless, overall, the relative changes with temperature in the " $e_{g} / t_{2 g}$ " empty orbitals ratio are expected to be a direct fingerprint of the changes in electronic structure associated with molecular spin crossover transition. This is again confirmed by theory (Figure 3 and supplementary materials). In the LS state, the " $e_{g} / t_{2 g}$ " low lying unoccupied molecular orbital density ratio is relatively large due to fully filled $t_{2 g}$-like molecular orbitals and empty $e_{g}$-like molecular orbitals, while for the high spin state, this " $e_{g} / t_{2 g}$ " ratio should be close to 1 because both the $e_{g}$ and $t_{2 g}$ Fe weighted low lying unoccupied molecular orbitals have similar partial densities.

\section{CONCORDANCE OF THE ELECTRONIC AND MAGNETIC STATES ?}

The $e_{g} / t_{2 g}$ XAS signature of the spin state as a function of temperature is presented in Figure 4, where it is compared with the magnetometry changes associated with the thermal transition. Using the temperature ( $\mathrm{T}_{\mathrm{XAS}}$ ) where the XAS data indicate a $50 \%$ occupancy of HS or LS, surprisingly, the data reveals an electronic structure transition at temperatures well below the spin crossover transition temperatures: $119 \pm 13 \mathrm{~K}$ for $\left[\mathrm{Fe}\left(\mathrm{H}_{2} \mathrm{~B}(\mathrm{pz})_{2}\right)_{2}(\right.$ bipy $\left.)\right], 141 \pm 7 \mathrm{~K}$ for $\left[\mathrm{Fe}\left(\mathrm{H}_{2} \mathrm{~B}(\mathrm{pz})_{2}\right)_{2}(\mathrm{phen})\right], \quad 140 \pm 11 \mathrm{~K}$ for $\left[\mathrm{Fe}(\mathrm{phen})_{2}(\mathrm{NCS})_{2}\right]$, and $164 \pm 7 \mathrm{~K}$ for $[\mathrm{Fe}(\mathrm{PM}-$ 
$\left.\mathrm{AzA})_{2}(\mathrm{NCS})_{2}\right]$ versus temperatures of $\sim 160 \mathrm{~K}$ for $\left[\mathrm{Fe}\left(\mathrm{H}_{2} \mathrm{~B}(\mathrm{pz})_{2}\right)_{2}(\right.$ bipy $\left.)\right], \sim 164 \mathrm{~K}$ for $\left[\mathrm{Fe}\left(\mathrm{H}_{2} \mathrm{~B}(\mathrm{pz})_{2}\right)_{2}(\mathrm{phen})\right], \sim 180 \mathrm{~K}$ for $\left[\mathrm{Fe}(\mathrm{phen})_{2}(\mathrm{NCS})_{2}\right]$, and $\sim 188 \mathrm{~K}$ for $\left[\mathrm{Fe}(\mathrm{PM}-\mathrm{AzA})_{2}(\mathrm{NCS})_{2}\right]$ $50 \%$ occupancy of the high spin state $\left(\mathrm{T}_{1 / 2}\right)$ derived from the molecular magnetic susceptibility. Both $T_{X A S}$ and $T_{1 / 2}$ are estimated assuming that the characteristic signatures of no occupancy of the high spin state occur at $80 \mathrm{~K}$ and those representative of $100 \%$ occupancy in the high spin state occur at $300 \mathrm{~K}$, as indicated in Figure 5.
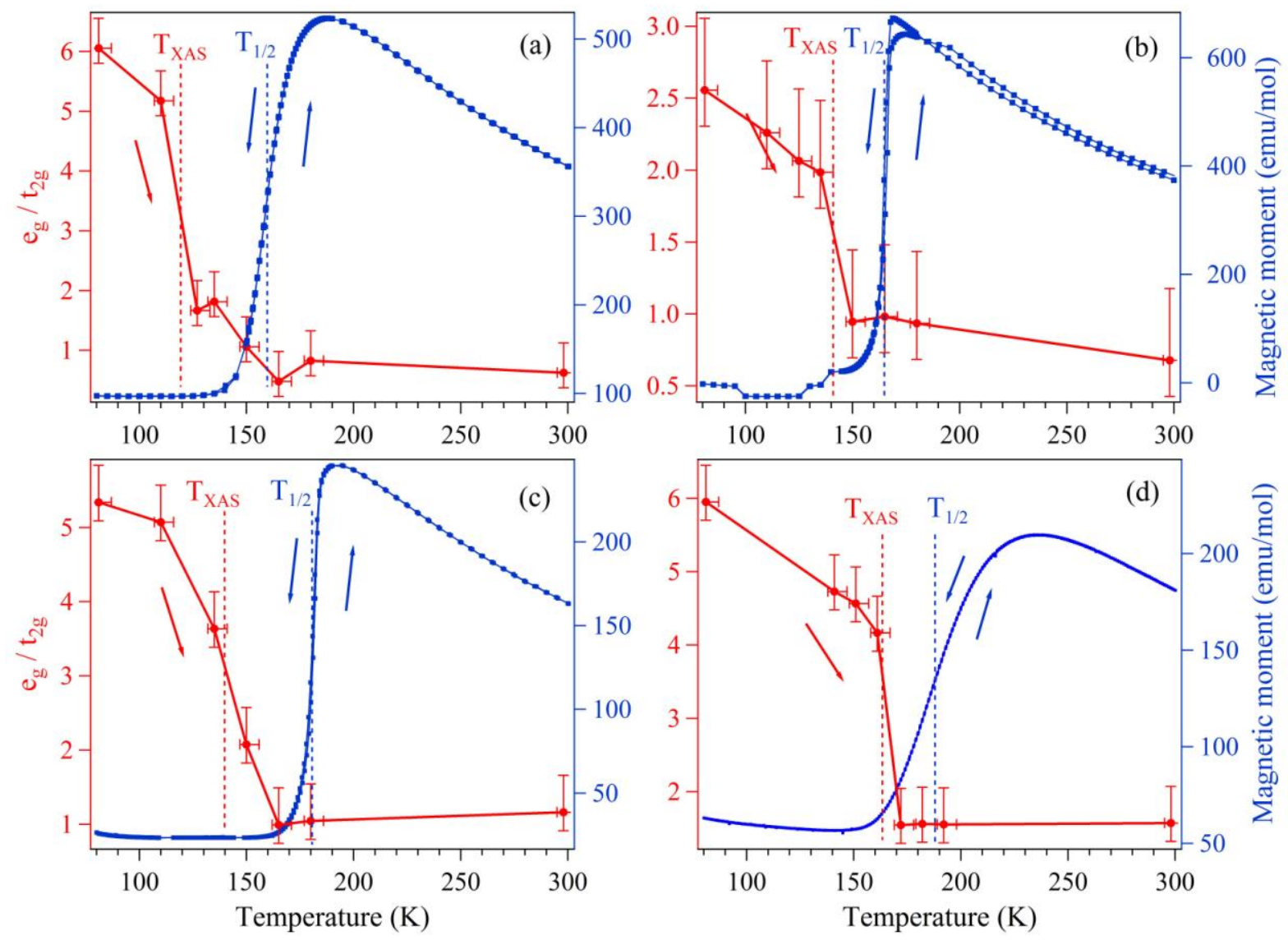

Figure 4. The temperature dependence of the relative magnetic moment (blue) compared to the relative empirical unoccupied " $e_{g} / t_{2 g}$ " molecular orbital state ratio (red) abstracted from the $X A S$ for (a) $\left[\mathrm{Fe}\left(\mathrm{H}_{2} \mathrm{~B}(\mathrm{pz})_{2}\right)_{2}\right.$ (bipy) $]$, (b) $\left[\mathrm{Fe}\left(\mathrm{H}_{2} \mathrm{~B}(\mathrm{pz})_{2}\right)_{2}(\mathrm{phen})\right]$, (c) $\left[\mathrm{Fe}(\text { phen })_{2}(\mathrm{NCS})_{2}\right]$ and (d) $\left[\mathrm{Fe}(\mathrm{PM}-\mathrm{AzA})_{2}(\mathrm{NCS})_{2}\right] . T_{1 / 2}$ identifies the thermal spin crossover transition identified from 
SQUID magnetometry and $T_{X A S}$ roughly identifies the transition in electronic structure indicated by the empirical " $e_{g} / t_{2 g}$ " ratio.

This temperature transition mismatch between XAS and the magnetometry measurements is systematic and unambiguous, especially when the data is recast as a plot of high spin (HS) or low spin (LS) state occupancy, as done in Figure 5. Such difference in temperature indicators of the spin crossover transition are not apparent in the detailed comparison of magnetometry and Mössbauer spectroscopy for $\left[\mathrm{Fe}\left(\mathrm{H}_{2} \mathrm{~B}(\mathrm{pz})_{2}\right)_{2}(\right.$ bipy $\left.)\right]$ and $\left[\mathrm{Fe}\left(\mathrm{H}_{2} \mathrm{~B}(\mathrm{pz})_{2}\right)_{2}(\mathrm{phen})\right]$. For these compounds no difference is seen between magnetometry and Mössbauer spectroscopy. ${ }^{23} \mathrm{We}$ emphasized in Figure 2 the isothermal XAS spectra indicative of roughly 50\% high spin (HS) state occupancy. We see in Figure 5 that $50 \%$ occupancy of the high spin states, indicated by XAS, occurs at temperatures where magnetometry data indicates more than $90 \%$ low spin (LS) molecules (using the conventional the molecular magnetic susceptibility $\chi_{M} \mathrm{~T}$, but plotted on a relative scale in Figure 5). Indeed the XAS data interpretation points towards a majority of the sample in the HS state well before the magnetometry shows a similar occupancy. Even if we reconsider our approach of using the $e_{g} / t_{2 g}$ ratio as spin state indicator, XAS spectrum and magnetometry data at these temperatures cannot be reconciled. This temperature difference in the indicators of the spin crossover transition, of typically 20 degrees or more, is valid for ALL four molecules studied. Systematic errors in samples temperature cannot be excluded from the XAS data, but have been minimized, as the XAS data was taken when heating the sample from the base temperature. The temperature difference we find in Figures 4 and 5 are at least 4 times larger than our highest estimate of error in measurement. Note that the temperature discrepancy cannot be explained by a SOXIESST-type effect either, as this would only stabilize the high spin 
state in the lowest temperature range (and in fact has been reported at temperatures below the range shown here).
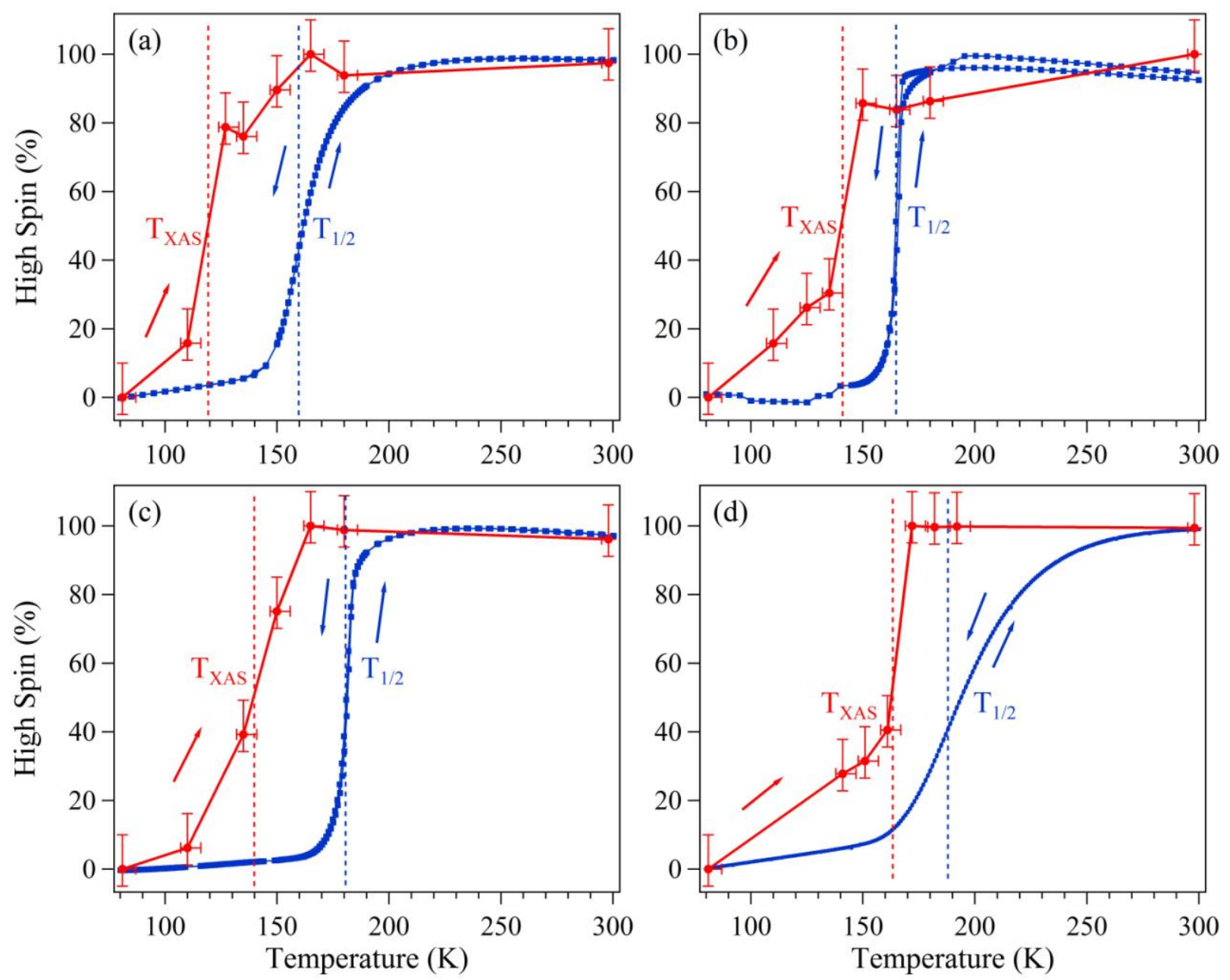

Figure 5. The temperature dependence of the occupancy of the high spin state as derived from the empirical unoccupied " $e_{g} / t_{2 g}$ " molecular orbital state ratio (red) abstracted from the XAS and from the relative molecular magnetic susceptibility $\chi_{M} T$ for (a) $\left[\mathrm{Fe}\left(\mathrm{H}_{2} \mathrm{~B}(\mathrm{pz})_{2}\right)_{2}\right.$ (bipy)], (b) $\left[\mathrm{Fe}\left(\mathrm{H}_{2} \mathrm{~B}(\mathrm{pz})_{2}\right)_{2}(\mathrm{phen})\right]$, (c) $\left[\mathrm{Fe}(\text { phen })_{2}(\mathrm{NCS})_{2}\right]$ and (d) $\left[\mathrm{Fe}(\mathrm{PM}-\mathrm{AzA})_{2}(\mathrm{NCS})_{2}\right]$. The demarcation $T_{1 / 2}$ identifies the thermal spin crossover transition identified from magnetometry while $T_{X A S}$ roughly identifies the transition in electronic structure indicated by the empirical " $e_{g} / t_{2 g}$ " ratio. 
Several scenarios for the origin of this complication in spin crossover transition temperature exist. First, the differences in sample environmental pressure, when performing the two types of experiments, might explain the difference in transition temperatures: SQUID magnetometry is performed in mbar partial He pressure, while XAS was performed under high vacuum conditions, at typically 4 to 6 orders of magnitude lower pressures. A sensitivity of the transition temperature to pressure is possible for spin crossover materials, ${ }^{51}$ and decreasing the pressure should diminish the transition temperature. Yet a difference of tens, if not hundreds, of MPa pressure would be generally (although, strictly speaking, not always) needed to change the critical temperature roughly $10 \mathrm{~K},{ }^{51}$ much less than the average $25 \mathrm{~K}$ temperature differences derived from XAS and magnetometry, so the pressure argument does not seem applicable to this case. Second, one should also recall that XAS is probing the first $5-10 \mathrm{~nm}$ of the sample surface, while magnetometry is a bulk measurement. This is of concern because while diffuse reflectance measurements for $\left[\mathrm{Fe}\left(\mathrm{H}_{2} \mathrm{~B}(\mathrm{pz})_{2}\right)_{2}(\mathrm{bipy})\right]$ and $\left[\mathrm{Fe}\left(\mathrm{H}_{2} \mathrm{~B}(\mathrm{pz})_{2}\right)_{2}(\mathrm{phen})\right]^{34}$ did not show any difference with the magnetometry data, nevertheless, differences up to $13 \mathrm{~K}$ for $\mathrm{T}_{1 / 2}$ were observed between evaporated thick films and bulk magnetic data. Therefore, one can speculate that the molecules at the surface of the micro-crystals exhibit a transition temperature lower than the bulk. Third, that in spite of claims that the magnetometry follows the structural transition of the spin crossover molecular complexes, ${ }^{7,49,50}$ structure and magnetometry are not in perfect lock-step. This latter possibility is suggested by Figure 6, as discussed below. 


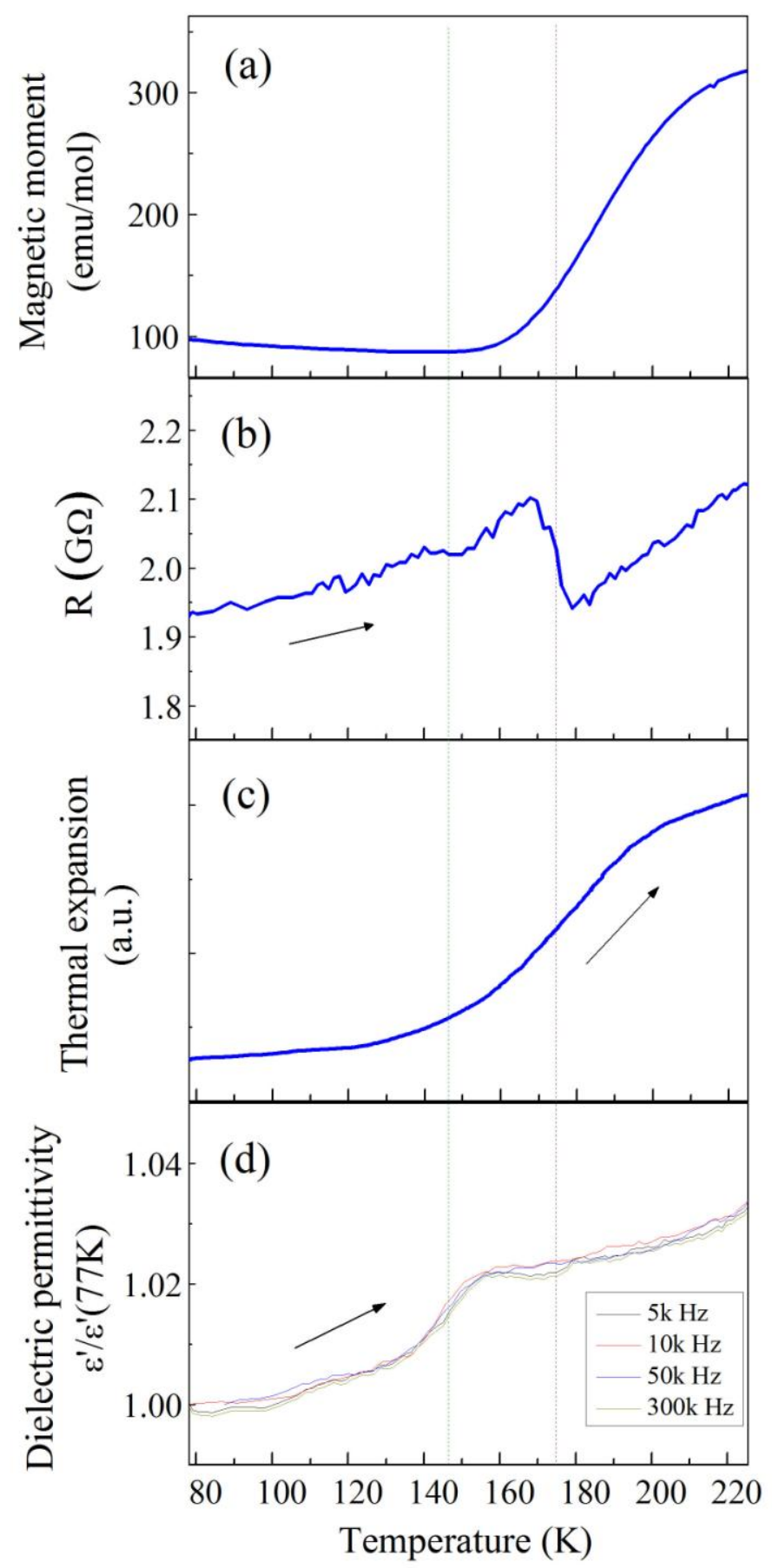

Figure 6. The spin crossover transition for $\left[\mathrm{Fe}(\mathrm{PM}-\mathrm{AzA})_{2}(\mathrm{NCS})_{2}\right]$ showing changes in (a) magnetometry (b) resistance (c) crystal expansion and (d) dielectric permittivity, which exhibits a transition temperature different from the (common) one of data (a)-(c). The vertical lines are to 
guide the eye as to the temperature placement of the significant changes in the transport measurements.

To bring further insight into the above evidence of complexity in the spin crossover transition, we have undertaken complementary characterization, investigating transport measurements of a single crystal of $\left[\mathrm{Fe}(\mathrm{PM}-\mathrm{AzA})_{2}(\mathrm{NCS})_{2}\right]$ as shown in Figure 6 . We compare data on thermal behavior for crystal size expansion and electrical properties, performed on [Fe(PM$\mathrm{AzA})_{2}(\mathrm{NCS})_{2}$ ] single crystals, to magnetometry data measured on a microcrystalline powder in a partial He background pressure (same as Fig. 5d). All three measurements were taken on the same crystal in the same environment. The change of crystal length is a macroscopic indicator of the change of crystalline structure, which tends to follow, as expected, the magnetic transition, and confirms that the environment pressure does not influence significantly the transition temperature, as is also expected. The structural transition is, however, much broader than the indicated transition from magnetometry. Yet the onset of the increasing unoccupied state signatures of high spin state occupancy in XAS, as indicated in Figure 5, occur at temperatures far below the accepted spin crossover transition temperature. This as well as the data of Figure 5 suggests that there is also a mismatch of the XAS derived electronic transition and the structural transition.

The observed high-value resistance exhibits a $10 \%$ change in the vicinity the $[\mathrm{Fe}(\mathrm{PM}-$ $\left.\mathrm{AzA})_{2}(\mathrm{NCS})_{2}\right]$ spin transition (magnetometry) temperature $(\sim 175 \mathrm{~K}$ versus $\sim 188 \mathrm{~K})$. The magnitude and trend should be interpreted with caution, as it might relate to contact resistance effects (two-points measurements geometry), which can possibly be altered by the minute geometrical changes of the crystal. However, there is clear departure for the dielectric 
permittivity, which shows a distinct change at temperature lower $(146 \pm 3 \mathrm{~K})$ than the magnetic transition, i.e. the transition in dielectric permittivity occurs at about the temperature where the XAS derived low lying unoccupied state $e_{g} / t_{2 g}$ ratio starts to significantly deviate from the ratio expected for the low spin state, as indicated in Figure 5d. Although the corresponding transition temperature, observed in the XAS $(164 \pm 7 \mathrm{~K})$, occurs after the change in the dielectric permittivity, we note that in both the dielectric permittivity and the XAS derived $e_{g} / t_{2 g}$ signature low lying unoccupied state ratios, the transition occurs well below the $\sim 188 \mathrm{~K}$ transition temperature indicated by the magnetometry for $\left[\mathrm{Fe}(\mathrm{PM}-\mathrm{AzA})_{2}(\mathrm{NCS})_{2}\right]$. These electrical data reveal a change at lower temperatures in dielectric permittivity and at higher temperature in resistivity but all the measurements were performed on the same sample, in the same environment, with the same apparatus. This finding, and its match to the XAS discrepancy discussed previously, suggest that environment and surface effects cannot be used to explain all the observed discrepancies in the transition temperatures. Previous results of Bousseksou and coworkers ${ }^{16}$ have shown no difference between dielectric constant and magnetic data, but these were polycrystalline samples and intergrain transport would dominate and mask any effect of the single crystal or single molecule.

The extensive literature on manganites has shown that electronic structure changes in this inorganic oxide need not precisely accompany a magnetic transition, and a charge order transition distinct from the magnetic transition occurs at lower temperatures. ${ }^{52-60}$ Current induced ${ }^{56-57}$ photo-induced ${ }^{58}$ and X-ray induced ${ }^{59-60}$ transitions from the charge ordered (lower temperature) state have also been reported. While the spin crossover molecular complexes are very different from the inorganic perovskites, the work with the manganites demonstrates there is no a priori reason that the final state must be reliable indicator of a unique spin state in the 
molecular initial state, when probed using an energetic excitation. The lesson we learned from these experiments in manganites is that different measurements of the electronic structure, magnetic moment, and electric transport measurements may exhibit different transition temperatures.

We therefore tentatively propose that final state effects (including many body effects, configuration effects, variously screened final states and second order multiple excitations) of the spectroscopy technique have an influence of the observed spin state spectroscopic fingerprint or that the structural transition of the spin crossover molecular complexes, ${ }^{7,49,50}$ and magnetometry are not in perfect lock-step. As this has not been observed above $100 \mathrm{~K}$, a long lived X-ray induced excited spin-state trapping akin to optical excitations that give rise to LIESST is unlikely, but X-ray absorption spectroscopy does produce a significant photocurrent. For this reason, an electrostatic ${ }^{12,13,61-62}$ or current ${ }^{9,10,11}$ induced transient switching the molecular spin state, in the vicinity of the spin crossover transition, ${ }^{13}$ is possible and might be associated with a change in the dielectric constant. Steric hindrance, including crystal packing, sample conductance and flux density would all then play a role in determining at what temperatures, this transient, not necessarily even metastable, electronic transition would occur. Yet the very demonstration that electron-induced (IESST) ${ }^{9}$ and soft X-ray induced excited spin state trapping $(\mathrm{SOXIESST})^{18}$ can lead to (meta)stabilization of the high spin states at low temperatures, while static fields ${ }^{33}$ can stabilize the hgigh spin state over a wide range of temperatures does suggest that small changes in dielectric constant could well lead to a sufficiently long lived transient state that bears some of the spectroscopic signatures of the high spin state in these Fe(II) spin crossovercomplexes. We have shown for the crystalline molecular ferroelectric copolymer 
poly(vinylidene fluoride (PVDF)-trifluoroethylene (TrFE)), that transient excitations can alter the unoccupied density of states measured in inverse photoemission. ${ }^{63}$

\section{CONCLUSION}

We have investigated the unoccupied electronic structure of several molecular spin crossover systems $\quad\left[\mathrm{Fe}\left(\mathrm{H}_{2} \mathrm{~B}(\mathrm{pz})_{2}\right)_{2}(\mathrm{bipy})\right], \quad\left[\mathrm{Fe}\left(\mathrm{H}_{2} \mathrm{~B}(\mathrm{pz})_{2}\right)_{2}(\mathrm{phen})\right], \quad\left[\mathrm{Fe}(\mathrm{phen})_{2}(\mathrm{NCS})_{2}\right], \quad$ and $\quad[\mathrm{Fe}(\mathrm{PM}-$ $\left.\mathrm{AzA})_{2}(\mathrm{NCS})_{2}\right]$ and combined with transport and permittivity data find that the spin crossover transition may be governed by several order parameters. The transition probed by different measurements would indicate several different spin crossover temperatures, distinct from the benchmark spin crossover transition temperature $\mathrm{T}_{1 / 2}$ indicated by magnetometry and Mossbauer. Thus caution about determining the spin crossover transition must be taken when applying final state spectroscopies as an accurate indicator of the spin crossover transition - this may not always be true. The possibility that a transient excited state, involving unoccupied electronic structure, might resemble the signatures of the high spin state is consistent with the observation that the spin crossover transition is influenced by electric field and current. In some respects, these results for the molecular spin crossover transition resemble the separation of the charge ordering transition from the ferromagnetic transition in the manganites.

\section{ASSOCIATED CONTENT}

Supporting Information. This supporting information provides a view of the L3 and L3 XAS spectra for $\left[\mathrm{Fe}\left(\mathrm{H}_{2} \mathrm{~B}(\mathrm{pz})_{2}\right)_{2}\right.$ (bipy)]; a more extensive description of the DFT calculations performed on $\left[\mathrm{Fe}\left(\mathrm{H}_{2} \mathrm{~B}(\mathrm{pz})_{2}\right)_{2}(\mathrm{bipy})\right]$, [ $\mathrm{Fe}\left(\mathrm{H}_{2} \mathrm{~B}(\mathrm{pz})_{2}\right)_{2}$ (phen)], [ $\left.\mathrm{Fe}(\mathrm{phen})_{2}(\mathrm{NCS})_{2}\right]$, and [ $\mathrm{Fe}(\mathrm{PM}-$ $\left.\mathrm{AzA})_{2}(\mathrm{NCS})_{2}\right]$ in both the high and low spin states, the basis for the assignment of the XAS 
features described in the paper; and detailed view of the effect of correlation on the unoccupied state occupancy.

\section{AUTHOR INFORMATION}

\section{Corresponding Author}

*Peter Dowben, Department of Physics and Astronomy, Theodore Jorgensen Hall, 855 North 16th Street, University of Nebraska-Lincoln, Lincoln, NE 68588-0299 U.S.A., tel: 402-4729838; FAX: 402-472-6148; e mail: pdowben@unl.edu

\section{Funding Sources}

This research was supported by the National Science Foundation through the Nebraska MRSEC (DMR-1420645). Partial financial support of the Agence Nationale de la Recherche (MULTISELF 11-BS08-06, Labex NIE 11-LABX-0058_NIE within the Investissement d'Avenir program ANR-10-IDEX-0002-02) and the International Center for Frontier Research in Chemistry (icFRC, Strasbourg) are also gratefully acknowledged. Use of the National Synchrotron Light Source, Brookhaven National Laboratory, was supported by the U.S. Department of Energy, Office of Basic Energy Sciences, under Contract No. DE-AC0298CH10886.

\section{ACKNOWLEDGMENT}

The authors acknowledge a number of helpful discussions with Jia Chen, Columbia University and Axel Enders (Nebraska). This research was supported by the National Science Foundation through the Nebraska MRSEC (DMR-1420645). Partial financial support of the Agence Nationale de la Recherche (MULTISELF 11-BS08-06, Labex NIE 11-LABX-0058_NIE within 
the Investissement d'Avenir program ANR-10-IDEX-0002-02) and the International Center for Frontier Research in Chemistry (icFRC, Strasbourg) are also gratefully acknowledged. Use of the National Synchrotron Light Source, Brookhaven National Laboratory, was supported by the U.S. Department of Energy, Office of Basic Energy Sciences, under Contract No. DE-AC0298CH10886. A critical reading of the manuscript by Dr. Samir F Matar (CNRS) is acknowledged.

\section{REFERENCES}

(1) Long, G. J.; Grandjean, F.; Reger, D. L. "Spin Crossover in Pyrazolylborate and Pyrazolylmethane Complexes," In Spin Crossover in Transition Metal Compounds I; Gütlich, P.,

Goodwin, H. A., Eds.; Topics in Current Chemistry, Springer: Berlin, 2004; 233, 91-122.

(2) Bousseksou, A.; Molnár, G.; Salmon, L.; Nicolazzi, W. Chem. Soc. Rev. 2011, 40, 3313.

(3) Létard, J.-F.; Guionneau, P.; Goux-Capes, L. "Towards Spin Crossover Applications”. In

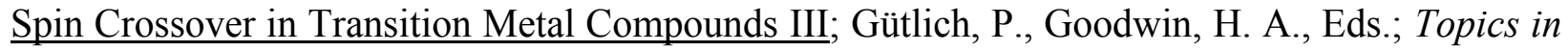
Current Chemistry, Vol. 235; Springer: Berlin, 2004; 235, 221-249.

(4) Halcrow, M. A. Chem. Soc. Rev. 2011, 40, 4119.

(5) Gütlich, P., Goodwin, H. A. "Spin Crossover-An Overall Perspective”. In Spin Crossover in Transition Metal Compounds I; Gütlich, P., Goodwin, H. A., Eds.; Topics in Current Chemistry, Vols. 233; Springer: Berlin, 2004; 233, 1-47.

(6) Gütlich, P.; Garcia, Y.; Goodwin, H. A. Chem. Soc. Rev. 2000, 29, 419.

(7) Guionneau, P.; Létard, J.-F.; Yufit, D. S.; Chasseau, D.; Bravic, G.; Goeta, A. E.; Howard, J. A. K.; Kahn, O. J. Mater. Chem. 1999, 9, 985. 
(8) Salmon, L.; Molnár, G.; Cobo, S.; Oulié, P.; Etienne, M.; Mahfoud, T.; Demont, P.; Eguchi, A.; Watanabe, H.; Tanaka, K.; Bousseksou, A. New J. Chem. 2009, 33, 1283.

(9) Gopakumar, T. G.; Matino, F.; Naggert, H.; Bannwarth, A.; Tuczek, F.; Berndt, R. Angew. Chem. Int. Ed. 2012, 51, 6262.

(10) Miyamachi, T.; Gruber, M.; Davesne, V.; Bowen, M.; Boukari, S.; Joly, L.; Scheurer, F.; Rogez, G.; Yamada, T. K.; Ohresser, P.; Beaurepaire, E.; Wulfhekel, W. Nat. Commun. 2012, 3, 938.

(11) Prins, F.; Monrabal-Capilla, M.; Osorio, E. A.; Coronado, E.; van der Zant, H. S. J. Adv. Mater. 2011, 23, 1545.

(12) Baadji, N.; Piacenza, M.; Tugsuz, T.; Sala, F. D.; Maruccio, G.; Sanvito, S. Nat. Mater. 2009, 8,813 .

(13) Mahfoud, T.; Molnár, G.; Bonhommeau, S.; Cobo, S.; Salmon, L.; Demont, P.; Tokoro, H.; Ohkoshi, S.-I.; Boukheddaden, K.; Bousseksou, A. J. Am. Chem. Soc. 2009, 131, 15049.

(14) Sato, O.; Tao, J.; Zhang, Y.-Z. Angew. Chem. Int. Ed. 2007, 46, 2152.

(15) Real, J. A.; Gaspar, A. B.; Muñoz, M. C. Dalton Trans. 2005, 2062.

(16) Bousseksou, A.; Molnár, G.; Demont, P.; Menegotto, J. J. Mater. Chem. 2003, 13, 2069.

(17) Lee, J.-J.; Sheu, H.; Lee, C.-R.; Chen, J.-M.; Lee, J.-F.; Wang, C.-C.; Huang, C.-H.; Wang, Y. J. Am. Chem. Soc. 2000, 122, 5742. 
(18) Warner, B.; Oberg, J. C.; Gill, T. G.; El Hallak, F.; Hirjibehedin, C. F.; Serri, M.; Heutz, S.; Arrio, M.-A.; Sainctavit, P.; Mannini, M.; Poneti, G.; Sessoli, R.; Rosa, P. J. Phys. Chem. Lett. 2013, 4, 1546.

(19) Gopakumar, T. G.; Bernien, M.; Naggert, H.; Matino, F.; Hermanns, C. F.; Bannwarth, A.; Mühlenberend, S.; Krüger, A.; Krüger, D.; Nickel, F.; Walter, W.; Berndt, R.; Kuch, W.; Tuczek, F. Chem. - Eur. J. 2013, 19, 15702.

(20) Létard, J.-F.; Chastanet, G.; Guionneau, P.; Desplanches, C. In Spin-Crossover Materials; Halcrow, L. a, Ed.; John Wiley \& Sons Ltd, 2013; pp 475-506.

(21) Marchivie, M.; Guionneau, P.; Howard, J. A. K.; Chastanet, G.; Létard, J.-F.; Goeta, A. E.; Chasseau, D. J. Am. Chem. Soc. 2002, 124, 194.

(22) Capes, L.; Létard, J.-F.; Kahn, O. Chem. - Eur. J. 2000, 6, 2246.

(23) Moliner, N.; Salmon, L.; Capes, L.; Muñoz, M. C.; Létard, J.-F.; Bousseksou, A.; Tuchagues, J.-P.; McGarvey, J. J.; Dennis, A. C.; Castro, M.; Burriel, R.; Real, J. A. J. Phys. Chem. B 2002, 106, 4276.

(24) Baadji, N.; Sanvito, S. Phys. Rev. Lett. 2012, 108, 217201.

(25) Aravena, D.; Ruiz, E. J. Am. Chem. Soc. 2012, 134, 777.

(26) Pronschinske, A.; Chen, Y.; Lewis, G. F.; Shultz, D. A.; Calzolari, A.; Buongiorno Nardelli, M.; Dougherty, D. B. Nano Lett. 2013, 13, 1429.

(27) Collison, D.; Garner, C. D.; McGrath, C. M.; Mosselmans, J. F. W.; Roper, M. D.; Seddon, J. M. W.; Sinn, E.; Young, N. A. J. Chem. Soc. Dalton Trans. 1997, 4371. 
(28) Oyanagi, H.; Tayagaki, T.; Tanaka, K. Phys. Scr. 2005, T115, 107.

(29) Hua, W.; Tian, G.; Fronzoni, G.; Li, X.; Stener, M.; Luo, Y. J. Phys. Chem. A 2013, 117, 14075.

(30) Bernien, M.; Wiedemann, D.; Hermanns, C. F.; Krüger, A.; Rolf, D.; Kroener, W.; Müller, P.; Grohmann, A.; Kuch, W. J. Phys. Chem. Lett. 2012, 3, 3431.

(31) Cartier dit Moulin, C.; Rudolf, P.; Flank, A. M.; Chen, C. T. J. Phys. Chem. 1992, 96, 6196.

(32) Zhang, X.; Palamarciuc, T.; Rosa, P.; Létard, J.-F.; Doudin, B.; Zhang, Z.; Wang, J.; Dowben, P. A. J. Phys. Chem. C 2012, 116, 23291.

(33) Zhang, X.; Palamarciuc, T.; Létard, J.-F.; Rosa, P.; Lozada, E. V.; Torres, F.; Rosa, L. G.; Doudin, B.; Dowben, P. A. Chem. Commun. 2014, 50, 2255.

(34) Palamarciuc, T.; Oberg, J. C.; Hallak, F. E.; Hirjibehedin, C. F.; Serri, M.; Heutz, S.; Létard, J.-F.; Rosa, P. J. Mater. Chem. 2012, 22, 9690.

(35) Madeja, K.; König, E. J. Inorg. Nucl. Chem. 1963, 25, 377.

(36) Létard, J.-F.; Guionneau, P.; Rabardel, L.; Howard, J. A. K.; Goeta, A. E.; Chasseau, D.; Kahn, O. Inorg. Chem. 1998, 37, 4432.

(37) http://www.nsls.bnl.gov/beamlines/beamline.asp?blid=u4b.

(38) Kundys, B.; Bukhantsev, Y.; Vasiliev, S.; Kundys, D.; Berkowski, M.; Dyakonov, V. P. Rev. Sci. Instrum. 2004, 75, 2192.

(39) Blöchl, P. E. Phys. Rev. B 1994, 50, 17953. 
(40) Kresse, G.; Hafner, J. Phys. Rev. B 1993, 48, 13115.

(41) Kresse, G.; Furthmüller, J. Phys. Rev. B 1996, 54, 11169.

(42) Liechtenstein, A. I.; Anisimov, V. I.; Zaanen, J. Phys. Rev. B 1995, 52, R5467.

(43) Real, J. A.; Muñoz, M. C.; Faus, J.; Solans, X. Inorg. Chem. 1997, 36, 3008.

(44) Gallois, B.; Real, J. A.; Hauw, C.; Zarembowitch, J. Inorg. Chem. 1990, 29, 1152.

(45) Beniwal, S.; Zhang, X.; Mu, S.; Naim, A.; Rosa, P.; Chastanet, G.; Liu, J.; Sterbinsky, G.

E.; Arena, D. A.; Dowben, P. A.; Enders, A. "Substrate-induced spin state locking of the [Fe(H2B(pz)2)2(bipy)] spin crossover complex", submitted to Phys.Chem.Chem.Phys.

(46) Scheer, A. M.; Burrow, P. D. J. Phys. Chem. B 2006, 110, 17751.

(47) Burrow, P. D.; Modelli, A. SAR QSAR Environ. Res. 2013, 24, 647.

(48) Komesu, T.; Le, D.; Zhang, X.; Ma, Q.; Schwier, E. F.; Kojima, Y.; Zheng, M.; Iwasawa, H.; Shimada, K.; Taniguchi, M.; Bartels, L.; Rahman, T. S.; Dowben, P. A. Appl. Phys. Lett. 2014, 105, 241602.

(49) Guionneau, P.; Lakhloufi, S.; Lemée-Cailleau, M.-H.; Chastanet, G.; Rosa, P.; Mauriac, C.; Létard, J.-F. Chem. Phys. Lett. 2012, 542, 52.

(50) Kulmaczewski, R.; Shepherd, H. J.; Cespedes, O.; Halcrow, M. A. Inorg. Chem. 2014, 53, 9809. 
(51) Ksenofontov, V.; Gaspar, A. B.; Gütlich, P. "Pressure Effect Studies on Spin Crossover and Valence Tautomeric Systems", In Spin Crossover in Transition Metal Compounds III; Topics in Current Chemistry; Springer Berlin Heidelberg, 2004; 235, 23-64.

(52) Uehara, M.; Cheong, S.-W. Europhys. Lett. 2000, 52, 674.

(53) Mazin, I. I.; Khomskii, D. I.; Lengsdorf, R.; Alonso, J. A.; Marshall, W. G.; Ibberson, R. M.; Podlesnyak, A.; Martínez-Lope, M. J.; Abd-Elmeguid, M. M. Phys. Rev. Lett. 2007, 98, 176406.

(54) Moritomo, Y.; Kuwahara, H.; Tomioka, Y.; Tokura, Y. Phys. Rev. B 1997, 55, 7549.

(55) Tomioka, Y.; Asamitsu, A.; Moritomo, Y.; Kuwahara, H.; Tokura, Y. Phys. Rev. Lett. 1995, $74,5108$.

(56) Song, H.; Tokunaga, M.; Imamori, S.; Tokunaga, Y.; Tamegai, T. Phys. Rev. B 2006, 74, 052404 .

(57) Asamitsu, A.; Tomioka, Y.; Kuwahara, H.; Tokura, Y. Nature 1997, 388, 50.

(58) Miyano, K.; Tanaka, T.; Tomioka, Y.; Tokura, Y. Phys. Rev. Lett. 1997, 78, 4257.

(59) Kiryukhin, V.; Wang, Y.; Chou, F.; Kastner, M.; Birgeneau, R. Phys. Rev. B 1999, 59, R6581.

(60) Kiryukhin, V.; Casa, D.; Hill, J. P.; Keimer, B.; Vigliante, A.; Tomioka, Y.; Tokura, Y. Nature 1997, 386, 813.

(61) Goswami, T.; Misra, A. Chem. - Eur. J. 2014, 20, 13951. 
(62) Droghetti, A.; Sanvito, S. Phys. Rev. Lett. 2011, 107, 047201.

(63) Rosa, L. G.; Jacobson, P. A.; Dowben, P. A. J. Phys. Chem. B 2006, 110, 7944.

Table of Contents Graphic and Synopsis

$\mathrm{X}$-ray absorption spectroscopy is compared with magnetometry across the spin crossover transition of several different Fe (II) complexes.

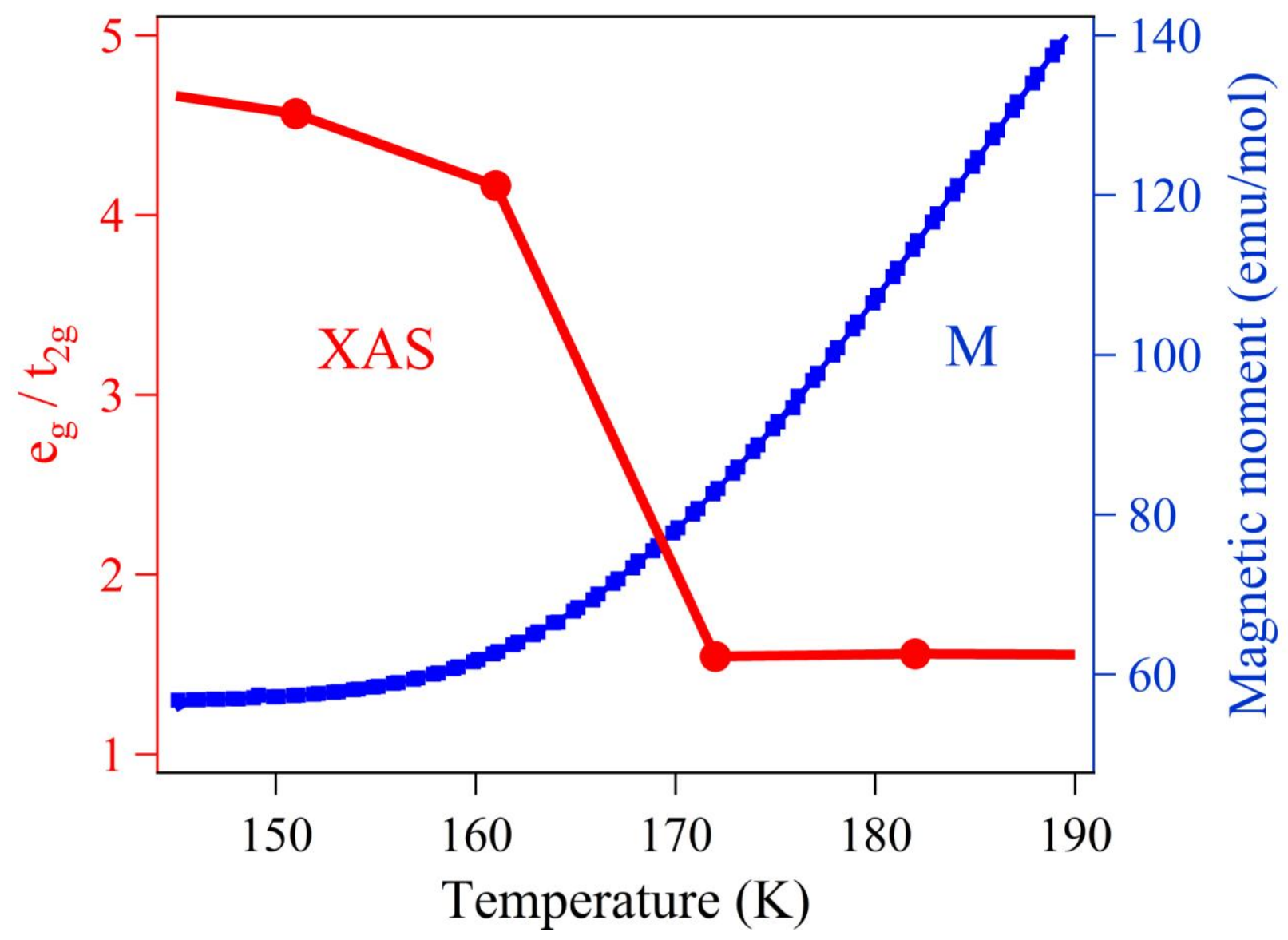

